\title{
The Relationship between Leisure Satisfaction and Happiness among College Students
}

\author{
Sabri Kaya \\ Faculty of Sport Sciences, Kirikkale University, Turkey
}

Copyright $\mathrm{C} 2016$ by authors, all rights reserved. Authors agree that this article remains permanently open access under the terms of the Creative Commons Attribution License 4.0 International License

\begin{abstract}
The purpose of this study was to examine the effect of the participation of college students in leisure activities and their level of leisure satisfaction on their happiness based on various parameters. A total of 1464 (females $=800$, males $=664$, ages ranging from 18 to 27 years) college students participated in the study. Study was conducted college students in Turkey between March and July, 2014. Data were collected using previously validated questionnaires namely Leisure Satisfaction Scale (LSS), Godin Leisure Time Exercise Questionnaire (LTEQ) and Oxford Happiness Scale (QHS). Data were analyzed using descriptive statistical techniques (frequency, arithmetic average, standard deviation), t-test, MANOVA, ANOVA and Pearson Correlation. According to analyses of scores of the Leisure Satisfaction Scale (LSS), the lowest average based on this factor was in the "Physical" dimension while the highest one was in the "Relaxation". The sub-dimension scores of "Educational," "Relaxation," "Physical" and "Aesthetic" was found significantly differences in terms of gender. Except for the "Physical" sub-dimension, in which a significant difference was detected, the average scores of female participants in the other three sub-dimensions were higher than male ones. Overall, a significant and positive relationship was found between all dimensions of leisure satisfaction on happiness.
\end{abstract}

Keywords Leisure Activity, Leisure Satisfaction, Happiness, College Student

\section{Introduction}

The quest for happiness has been a human concern and the most universal human desire throughout the history of humanity. And also happiness is a highly important ideal of life, regarded as a criterion of a good and quality life in all cultures in the world. Over the past several decades, scientific concern, especially in the field of psychology and leisure has focused on the relationships between well-being, satisfaction, hope, optimism and happiness at the level of individual or certain groups (Argyle [4]; Myers and Diener [76]; Diener [25]; Lu and Shih [68]. In recent years, the close relationship of happiness or subjective well-being with making use of leisure time and leisure satisfaction has been among the research topics of many social scientists (Beard and Ragheb [10]; Robert[84]; Caldwell [15]; Godbey [37]; Robinson and Godbey [85]. Leisure has gradually become an inevitable and significant part of the lives of those living in contemporary societies. Leisure is psychological and social functions make it an important contributor to the quality of people's lives, meaning how good, satisfied, happy and content they feel (Roberts [84]. It can be said that leisure has become an increasingly expected and important part of people's lives in modern societies. Previous research has shown that leisure participation is positively linked to psychological well-being or happiness as well as physical health (Caldwell [15]. Godbey [37] stated that leisure and recreation are critical in one's life because people proactively seek good health when participating in leisure and recreation. Leisure time provides the best opportunity for people to do what they want to do and to pursue pleasure, happiness and self-expression (Robinson and Godbey [85]. However, leisure activities are major sources of happiness. They are of special interest because their selection is a matter of individual choice and they are more under personal control than many other sources of satisfaction (Hills and Argyle [48]. In addition to producing temporary states of joy, leisure is a major source of happiness. Many studies, for example Headey and Wearing [46], have found strong positive correlations between life satisfaction and leisure satisfaction. Other studies using experimental and quasi-experimental designs have demonstrated the causal influence of leisure on life satisfaction and happiness (Argyle [5].

Parham [79] and Iso-Ahola [55] regard leisure time as a source that provides various benefits in terms of social, physical, mental and emotional development in every phase of life, especially in childhood and in adolescence. However, in adulthood, they point out that leisure time activities are a factor that increases general satisfaction levels and happiness, and that help to relieve stress and to escape routine. 
Beard and Ragheb [10] define leisure satisfaction as the satisfaction gained as a result of choosing leisure time activities of which one has a positive perception, and point out that it plays a dynamic role in one's life to make use of leisure time and to be aware of the fact that there is a relationship between leisure choices and concepts such as personal and social adaptation, psychological health and general happiness. Being aware of these relationships could enable individuals to improve their quality of life. Happiness or personal well-being as a value and an ideal of life that indicates the quality of life of individuals and of societies is a concept which must be focused on for the existence of a good life and a good society (Diener et al., [30]. Universities are where the young population is demographically the highest. University education is a period which plays an important role in those young people's lives. At university, a young person meets the need for education in the first instance, but also meets many other social and personal needs. Among the most important is the need for personal happiness or well-being. Previous studies have indicated that the satisfaction of participation in leisure during university education has improved the students' university experience by positively affecting them in terms of physical, social, and psychological aspects (Nesbit [77]; Todaro [94].; Wilson[99]; Dost [33]. Within this context, the participation of the young population at universities in indoor or outdoor recreation activities so as to use leisure is going to contribute both their satisfaction of leisure and their personal happiness.

The purpose of the present study was to explore the effect of the participation of university students in leisure time activities and their level of leisure satisfaction on their state of happiness based on various parameters (according to psychological, education, social, relaxation, physiological and aesthetic dimensions).

\section{Literature Review}

A considerable amount of literature exists that suggests leisure time activity participation is associated with an improved sense of psychological well-being or happiness. There is a positive and significant relationship between the use of leisure and the happiness of the individual as well as the happiness of society (Parham [79]; Iso-Ahola [55]; Argyle [4].; Myers and Diener [76]; Diener [25] Lu and Shih [68]; Beard and Ragheb [10]; Peterson and Seligman [80]; Abdel-Khalek[1]; Lyubomirsky [70]; Stebbins [92]. It would appear that leisure is an aspect of life which plays an integral part in the general happiness of an individual. The place and the effect of leisure on an individual's and society's pursuit of happiness is a global subject that attracts not only today's scientists, but also philosophers from every phase of human history, and it dates back to the first existence of man. This concern goes back almost 2500 years to the prominent philosophers of their time from East to West, including Confucius, Buddha, Al-Ghazali, Socrates, Plato and Aristotle. In fact, Aristotle emphasized the significance of leisure by suggesting that it is more significant than work life since leisure triggers joy and happiness in life. He also claimed that happiness is the main goal of life and is what you understand it to be, and also that it is the overall aim and target of the existence of a human being. Similarly, Socrates implied that happiness and personal development were the main goals of life and the main purpose at the center of education (Aristotle [7]. Indeed, many researchers and thinkers have attributed adaptation and good mental health to the capacity for being happy and satisfied with life (e.g., Diener [24]; Taylor and Brown [93].

\section{Leisure and Happiness}

In surveys carried out in different cultures, when people were asked what they wanted most in their lives, they placed "happiness" at the top of the list (Diener [25]. Happiness is defined as the evaluation of life in terms of cognitive and affective aspects. According to this, a person is assessed to be happy if he frequently experiences positive emotions such as joy, pride, trust, excitement, if he rarely experiences negative feelings like anger, horror, anxiety and hate, and if he gains much satisfaction from the different domains of life, family, work, career etc. (Argyle et al.,[6]; Diener [24]; Lyubomirsky [70]. In other words, happiness or personal well-being is therefore defined as frequently experiencing positive emotions, rarely experiencing negative emotions and gaining high levels of satisfaction (Diener [24]; Myers and Diener [76]. The concept of happiness has been revealed over the years in various perspectives, from the subjective appreciation the individual feels for himself with his own material or sentimental values, to his owning the values that help him gain society's appreciation, and to the combination of these in various rates, and to his satisfaction with the lifestyle he leads. However, the focus today is on perceived happiness; whether an individual feel happy or not as an outcome of their own assessment of their inner selves, and what makes them feel happy. For this reason, happiness or subjective well-being reflects the positive aspect of mental health.

In the literature, subjective well-being is substituted for the concept of happiness (Diener [25] and it is the person's assessment of his life cognitively and emotionally (Diener [24]. Cognitive assessment involves judgments as regards life satisfaction, while emotional assessment includes emotional reactions that are both satisfactory and unsatisfactory. The individual gains satisfaction from life with the help of cognitive evaluation, and he is able to feel positive emotions that satisfying him more often than negative feelings that do not (Diener and Diener [26] However, happiness, an important variable in terms of life, is defined as the level of satisfaction felt in some private experiences, the state of the positive sensation that is perceived, the frequency of this positive sensation (Cheng and Furnham [17] and the degree of the individual's assessment of his own life (Abdel-Khalek [1]. Some researchers use happiness and life satisfaction synonymously 
and define them as similar experiences (Peterson and Seligman [80]; Abdel-Khalek [1].

Studies carried out into happiness tend to focus generally on the sources of happiness. When it is dealt with in this respect, Grinde [42] points out that happiness is the indirect result of the development in human nature and happiness is the main and natural purpose of human life when all cultures are considered. Giblin [36] attributes the source of happiness to success and the satisfaction gained in every domains of life, including work experiences and human relations; however, he points out that the ability to keep healthy human relations alone is not a guarantee for happiness. On the other hand, Crossley and Landridge [19] similarly show the source of the happiness as social relations, professional life and leisure activities. Peterson and Seligman [80] suggest that there are three different dimensions of life satisfaction and happiness, and order them as enjoying life, finding meaning in life, and leaning to, attaching to or focusing on a situation, a person or a life. Abdel-Khalek [1] has also discovered that there is a significant relationship between happiness and such states as optimism, hope for the future, high self-esteem, positive sensations, and extroversion and feeling oneself physically and psychologically healthy. The fact that benefits received from leisure enhance personal happiness has been revealed by previous research (Hallab [44] and additionally those benefits are also a means of making human beings better (Pichly[81], helps to improve people's feeling of happiness (Ateca-Amestoy et al.[8]; Spiers and Walker [91]. By changing their actions, people enhance their happiness (Sheldon and Lyubomirksy [89], and those actions may include spending time for social relations (Diener and Seligman [30] or taking an active part in sports (Hills \& Argyle [48] to enhance happiness.

Some previous studies have indicated that pleasant participation in leisure and the benefits of leisure are positively linked to happiness at a significant rate (Reich \& Zautra [82], to happiness at a higher level (Lin [63] and are an important precursor to happiness ( $\mathrm{Lu} \& \mathrm{Hu}$ [67]. Findings of some earlier surveys have indicated that unhappy people are less healthy than those who are happy and that happy people outperform those who are less happy. Happy people are also more prolific, get more involved in social relations, and earn more money (e.g., Diener [25]; Lyubomirsky, King and Diener [71]; Lyubomirksy, Sheldon and Schakade [72]. As a result, happiness can be promoted by participating in leisure and receiving the advantages of leisure $(\mathrm{Lu}$ and Argyle [66]; Currier [22]. Moreover, Csikszentmihalyi [20] asserted that creating and discovering new things provide happiness. It should not be forgotten that these qualifications may also result from leisure and recreation even though they are thought to derive from creative work.

\section{Leisure Satisfaction and Happiness}

Another important concept in studies concerned with those who participate in leisure activities and that is linked to leisure is happiness and leisure satisfaction. Beard and Ragheb[10] note that leisure satisfaction is the satisfaction gained as a result of choosing leisure time activities of which one has positive perceptions. Similarly, Seigenthaler [89] defines leisure satisfaction as the positive emotions that individuals acquire as a result of meeting their personal needs by taking part in leisure activities and in some way, he refers to personal happiness. Leisure satisfaction correlates to happiness, and social aspects of leisure satisfaction predict happiness in longitudinal analyses ( $\mathrm{Lu}$ and Argly [70]. In addition to this, there have been various studies carried out that indicate that especially active participation in leisure activities creates a positive feeling in individuals (Caldwell and et al. [14]; Kaya [60]; Murphy [75]. In fact, according to some earlier research, activities done passively have been negatively associated with well-being, while active involvement in leisure has been positively connected with more well-being (Csikszentmihalyi and Hunter [21]; Holder, Coleman and Sehn [50]. A study recently conducted by Wang and et al. [98] discovered that unhappiness could be relieved over time by a shift from an inactive state to an active state. Furthermore, if a shift occurs from an active state to an inactive one, the possibility of being unhappy increases in two years' time. So one of the important points to learn from this research is the suggestion that you should become and stay active and as a result you will avoid unhappiness. With the support of these data, leisure satisfaction can be defined as the state of meeting physiological and emotional expectations by means of the active or passive activities an individual participates in voluntarily in order to acquire new and different skills without depending on external forces, and to gain the feelings of health, amusement, satisfaction, refreshment and happiness for health, social, cultural, sportive or artistic needs without expecting a material benefit.

Previous studies indicate that leisure participation was affected by such different variables as time, gender, age, income, welfare level, physical and psychological health, professional differences and personal characteristics, and it is also linked to various satisfaction levels and variables such as life quality, occupational satisfaction, level of happiness, satisfaction with marriage, work stress and the satisfaction from bilateral relations (Brown and Frankel [12]; Berg et al. [11]; Lloyd and Auld [65]; $\mathrm{Lu}$ and $\mathrm{Hu}$ [67]; Vong Tze [96]; Iwasaki [56]. Similarly, the concern for happiness or well-being has also been on the rise in Turkey. In recent years, leisure, happiness and life satisfactions are among the topics on which some Turkish research has focused (e.g., Dogan [32]; Dost [33]; Koker [62]; Aydin [9]; Karakatipoglu [58]; Cenkseven [16]. However, in a study carried out by Ardahan and Lapa [2] on 804 university students, it was found that leisure satisfaction and its sub-dimensions do not differ according to gender, but that the level of leisure time satisfaction increases in parallel with the increase in income level. Diener et al. [28], on the other hand, point out those university students all over the world regard happiness as highly important in their lives. The impact which leisure had on physical and mental well-being was studied by Kim [61] and he found that leisure had favorable effects on 
physical as well as mental well-being. Moreover, because the patterns and behaviors of leisure which have long-term possible results for shaping future leisure behaviors and attitudes are developed by the students themselves, the satisfaction with leisure is especially important during the college years (Gordon and Catalbiano [41]; Hultsman [54]; Kaya [60]; Dost [33]. As long as an individual has positive and satisfactory leisure experiences, the chance of his participation in leisure activities following his college years increases. When they examined the behavior patterns of leisure over life span, Searle, Mactavish, and Brayley [86] revealed that one of the main factors helping to explain people's choice to go on participating in leisure activities was their satisfaction with leisure. Furthermore, it has also been proven that gratifying participation in leisure throughout college education highly enhances the college experience in that it has physical, psychological and social effects on students (Nesbit [77]; Todaro [94]; Wilson [99]; Dost [33]. Similarly, in terms of establishing life-long leisure patterns, pleasing leisure experiences play an important role during college. Knowing what encourages people to take part, and how that encouragement affects a satisfying experience can help people to understand those experiences better. For modern young people, work has been replaced with leisure time as one of the most significant aspects of life. The reason behind this is that there is a positive correlation between quality of life, happiness and personal well-being and enjoying leisure time (Argyle [4].

Western examples have dominated the literature on leisure until recently. Some research (Liu, Yeh, Chick and Zinn [64]; Horne [51]; Walker and Wang [97]; Gurbuz and Henderson [43], as an alternative to the Western dominance in leisure, provides a non-Western way of thinking about leisure. This study aims to show the effect of the involvement in leisure activity and leisure satisfaction on happiness in Turkish youth. In this study, as a different perspective from the research carried out mainly in Westerns countries until now, we aimed to analyze the dimensions of the link between happiness and leisure satisfaction in Turkish university students, who have recently started to understand the importance of leisure and who have habits of culture, belief and life different from those of the West, by looking at the habits of leisure, the level of leisure involvement and the leisure activities.

\section{Materials and Methods}

In this research, a descriptive research model, which was frequently used in the field of social sciences in compliance with the research questions of the study, was used (Buyukozturk and et al. [13]. This study aimed to evaluate the effect of the leisure satisfaction levels and leisure participation of students from different departments of different universities in Turkey on their happiness according to various parameters (according to such dimensions as psychological, educational, social, relaxation, physiological and aesthetic). Accordingly, the dependent variable of the research was determined as individual happiness, while the independent variable was determined as leisure satisfaction.

\section{Participants}

The present sample consisted of 1464 college students attending a public and private universities located in the Central Anatolian region of the Turkey. A total of 1500 survey questionnaires were distributed to six universities, with a convenience sampling method utilized to ensure adequate representation. Accordingly, a total of 1500 subjects were recruited from six universities across the country, and a total of 1464 valid survey questionnaires were returned for a valid response rate of $97.6 \%$. The ages of the participants ranged from 18 to 27 years $($ Mwomen $=21.09$, $\mathrm{SD}=1.90$ and $\mathrm{Mman}=21.87, \mathrm{SD}=2,24)$. In addition, 664 participants were male $(45.4 \%)$, while 800 were female $(54,6 \%)$.

\section{Measures}

Data were collected using previously validated questionnaires/scales namely Leisure Satisfaction Scale (LSS), Godin Leisure Time Exercise Questionnaire (LTEQ) and Oxford Happiness Scale (QHS). For demographic information, subjects' personal background information was recorded, such as age, gender, income, class, and university major. In order to determine individuals' levels of leisure participation, the level of leisure satisfaction and their relationship with personal happiness, the Leisure Satisfaction Scale/ LSS developed by Beard and Ragheb [10] was used. To discover the individual's exercise habits during usual leisure time, the Godin Leisure Time Exercise Questionnaire/LTEQ of Godin was used, and so as to assess the happiness level of the individuals, the Oxford Happiness Questionnaire- Short Form/OHQ-SF developed by Hills and Argly [48] was utilized.

\section{Leisure Time Exercise Behavior}

Leisure Time Exercise Questionnaire (LTEQ) developed by Godin and Shepherd [38] and adapted by Godin [39], is a simple instrument to measure a person's leisure time exercise behavior. It was designed to be reliable, valid and easy to complete quickly without the need for detailed review.

\section{Leisure Satisfaction}

The leisure satisfaction of participants was measured with Beard and Raheb's 'Leisure Satisfaction Scale' (Beard and Ragheb [10]. Participants responded to items on a 5-point Likert Scale. Six aspects of leisure satisfaction were tapped: psychological, social, physical, educational, relaxation, and aesthetic. This questionnaire is a good way to get a snapshot of participants' current level of leisure satisfaction. The scale was adapted into Turkish by Gokce and Orhan [40]. In the present study, while the internal consistency of the scale was .91; the internal consistency coefficients for the sub-dimensions of the scale were found to be $.78, .69, .82, .74, .75$ and .76 respectively. A higher total score indicated a higher level of overall leisure satisfaction. 
In this study, the Cronbach alpha coefficient was between 0.74 and 0.80 respectively. Participants were required to rate their satisfaction on 5 -point scales $(1=$ very dissatisfied, $5=$ very satisfied).

\section{Happiness Questionnaire}

The Oxford Happiness Questionnaire-Short Form (OHQ-SF): The OHQ-SF was developed by Hills and Argyle [48]. This questionnaire is a good way to get a snapshot of participants' current level of happiness and the OHQ_SF was used to measure perceived level of happiness, composed of positive affect, (lack of) negative affect, and life satisfaction. A higher total score indicated a higher level of overall happiness. In this study, the Cronbach alpha coefficient was 0.94. The scale consists of seven items. It has a correlation of .93 $(\mathrm{p}<.001)$ with the original scale, which consisted of 29 items. The Turkish adaptation of the scale was carried out by Dogan and Cotok [31].

\section{Data Analyses}

In the assessment of the data, descriptive statistical techniques (frequency, arithmetic average, standard deviation) were used by SPSS 20 version, whereas for independent samples, t-test and single factorial MANOVA and ANOVA were used in determining the differences between variables. Moreover, in order to determine the correlations between the variables, Pearson Correlation tests were used. It was decided whether data met the prerequisites for parametric tests by analyzing the values of Skewness and Kurtosis (normal distribution status of data) and the results of Levene test (the equation of the variances) (Buyukozturk [13].

Table 1. Distribution of Scale Scores

\begin{tabular}{|c|c|c|c|c|}
\hline Scales & Number of Items & $\mathrm{N}$ & & SD \\
\hline Happiness Scale & 7 & 1448 & 3.25 & 0.59 \\
\hline Leisure & & & & \\
\hline Psychological & 4 & 1456 & 3.33 & 0.87 \\
\hline Educational & 4 & 1457 & 3.64 & 0.83 \\
\hline Social & 4 & 1459 & 3.59 & 0.79 \\
\hline Relaxation & 4 & 1458 & 3.80 & 0.83 \\
\hline Physical & 4 & 1457 & 3.20 & 0.89 \\
\hline Aesthetic & 4 & 1458 & 3.46 & 0.84 \\
\hline
\end{tabular}

\begin{tabular}{|c|c|c|c|c|c|c|c|c|c|c|c|c|c|c|c|}
\hline \multirow{2}{*}{ Scales } & \multicolumn{3}{|c|}{ Female } & \multicolumn{3}{|c|}{ Male } & \multicolumn{3}{|c|}{ Never } & \multicolumn{3}{|c|}{ Sometimes } & \multicolumn{3}{|c|}{ Often } \\
\hline & $\mathrm{N}$ & & SD & $\mathrm{N}$ & & SD & $\mathrm{N}$ & & SD & $\mathrm{N}$ & & SD & $\mathrm{N}$ & & $\mathrm{SD}$ \\
\hline $\mathrm{HS}$ & 790 & 3.23 & .59 & 658 & 3.27 & .60 & 355 & 3.03 & .92 & 650 & 3.27 & .58 & 443 & 3.38 & .59 \\
\hline LSS & & & & & & & & & & & & & & & \\
\hline Psychological & 782 & 3.35 & .86 & 650 & 3.31 & .88 & 351 & 2.98 & .82 & 642 & 3.35 & .77 & 439 & 3.60 & .87 \\
\hline Educational & 782 & 3.72 & .82 & 650 & 3.57 & .83 & 351 & 3.33 & .89 & 642 & 3.70 & .73 & 439 & 3.82 & .85 \\
\hline Social & 782 & 3.63 & .77 & 650 & 3.56 & .81 & 351 & 3.32 & .82 & 642 & 3.60 & .73 & 439 & 3.81 & .77 \\
\hline Relaxation & 782 & 3.87 & .81 & 650 & 3.73 & .85 & 351 & 3.48 & .88 & 642 & 3.82 & .76 & 439 & 4.03 & .81 \\
\hline Physical & 782 & 3.12 & .89 & 650 & 3.30 & .88 & 351 & 2.98 & .91 & 642 & 3.22 & .84 & 439 & 3.35 & .92 \\
\hline Aesthetic & 782 & 3.50 & .85 & 650 & 3.41 & .84 & 351 & 3.20 & .92 & 642 & 3.50 & .77 & 439 & 3.61 & .84 \\
\hline
\end{tabular}


Table 3. Distribution of the scale scores according to Income level variable.

\begin{tabular}{|c|c|c|c|c|c|c|c|c|c|c|c|c|}
\hline \multirow{2}{*}{ Scales } & \multicolumn{3}{|c|}{ Less than 500TL } & \multicolumn{3}{|c|}{$501-1000 \mathrm{TL}$} & \multicolumn{3}{|c|}{$1001-1500 \mathrm{TL}$} & \multicolumn{3}{|c|}{$1501 \mathrm{TL} \geq$} \\
\hline & $\mathrm{N}$ & & $\mathrm{SD}$ & $\mathrm{N}$ & & SD & $\mathrm{N}$ & & SD & $\mathrm{N}$ & & SD \\
\hline HS & 525 & 3.19 & .59 & 533 & 3.26 & .58 & 189 & 3.25 & .55 & 201 & 3.35 & .64 \\
\hline LSS & & & & & & & & & & & & \\
\hline Psychological & 522 & 3.24 & .87 & 521 & 3.35 & .886 & 186 & 3.35 & .81 & 203 & 3.48 & .88 \\
\hline Educational & 522 & 3.61 & .83 & 521 & 3.69 & .82 & 186 & 3.60 & .80 & 203 & 3.66 & .83 \\
\hline Social & 522 & 3.53 & .79 & 521 & 3.64 & .77 & 186 & 3.58 & .78 & 203 & 3.64 & .80 \\
\hline Relaxation & 522 & 3.75 & .85 & 521 & 3.84 & .79 & 186 & 3.76 & .86 & 203 & 3.88 & .81 \\
\hline Physical & 522 & 3.18 & .88 & 521 & 3.19 & .91 & 186 & 3.17 & .84 & 203 & 3.27 & .90 \\
\hline Aesthetic & 522 & 3.37 & .85 & 521 & 3.49 & .83 & 186 & 3.39 & .81 & 203 & 3.65 & .85 \\
\hline
\end{tabular}

Table 4. The results of the correlation between the scores of HS and LSS

\begin{tabular}{|c|c|c|c|c|c|c|c|}
\hline & Happiness Scale & Psychological & Educational & Social & Relaxation & Physical & Aesthetic \\
\hline Happiness Scale & 1 & & & & & & \\
\hline Psychological & $.287^{* *}$ & 1 & & & & & \\
\hline Educational & $.272^{* *}$ & $.614^{* *}$ & 1 & & & & \\
\hline Social & $.237^{* *}$ & $.528^{* *}$ & $.621^{* *}$ & 1 & & & \\
\hline Relaxation & $.229^{* *}$ & $.527^{* *}$ & $.549^{* *}$ & $.555^{* *}$ & 1 & & \\
\hline Physical & $.250^{* *}$ & $.426^{* *}$ & $.378^{* *}$ & $.322^{* *}$ & $.332^{* *}$ & 1 & \\
\hline Aesthetic & $.265^{* *}$ & $.440^{* *}$ & $.474^{* *}$ & $.478^{* *}$ & $.464^{* *}$ & $.410^{* *}$ & 1 \\
\hline
\end{tabular}

ANOVA analysis results revealed that the HS scores of the participants showed statistically significant difference according to the income variable $\mathrm{F}(3,1444)=3.845, \mathrm{p}<0.05$. The average score of participants with an income of $1501 \mathrm{TL}$ or more was higher than those of the participants who have a lower level of income (Table 3). The results of the MANOVA analysis of the impact of income level on the LSS sub-dimension showed that the difference that emerged was significant $\lambda=0.976, F(6,1425)=4.610, p<0.05$. According to one-way ANOVA outcomes of the variable of income level, it was concluded that the 'Psychological' $[\mathrm{F}(3,1428)=4.174$, $\mathrm{p}<0.05$ and 'Aesthetic' $\mathrm{F}(3, \quad 1428)=5.905$, $\mathrm{p}<0.01$ sub-dimensions scores differed significantly. In both sub-dimensions in which a significant difference was discovered, the average scores of the participants with higher levels of income was higher than those of the other participants (Table 3 ).

In addition, according to the results of the correlation analysis conducted, there was a positive and slightly significant relationship between the scores of the Happiness Scale and the scores of all Leisure Satisfaction Scale sub-dimensions (Table 4).

\section{Conclusions}

The purpose of this study was to assess the impact of the participation of students, studying in different departments of universities in different parts of Turkey in leisure time activities and the level of leisure satisfaction on their happiness according to various parameters (according to psychological, educational, social, relaxation, physiological and aesthetic dimensions). When the Leisure Satisfaction Scale was studied, it was determined that the lowest average on the basis of sub-factors was in the dimension of 'physical' (3.20), while the highest average was in the 'relaxation' dimension (3.80). Analysis revealed that there was a difference in the level of significance according to leisure satisfaction levels of female and male participants. Except for the 'Physical' sub-dimension, compared with the leisure satisfaction levels of males, those of the females in psychological, educational and relaxation sub dimensions are higher. Various results have appeared when the research regarding this topic in the literature was examined. In some studies, a significant difference emerged in leisure satisfaction level in terms of gender (Kabanoff [57]; Vong Tze [96].

Especially in his study, Kabanoff [57] suggested that the leisure satisfaction level of males was more dominant compared with that of females, whereas he emphasized that females' need for leisure for social interaction in particular is greater. In terms of these outcomes, our study shows a similarity. However, similar results could not be found according to the gender variable in most of the research carried out regarding leisure satisfaction levels (Riddick [83]; DiBona [23]; Ardahan and Lapa [2]. The remarkable point of the study was that the Happiness Scores of the participants did not show any significant differences according to the gender variable, while a difference in the significance level appeared in the levels of leisure satisfaction of both male and female participants $(t=1.093 ; p>0.05)$. When the literature 
was looked through, most of the research done on different age groups showed that there were no significant links between individual happiness and gender and showed parallelism with the study done in terms of consequences (Hampton and Marshall [45]; Fugl-Meyer, Melin and Fugl-Meyer [35]; Hintikka [49] ; Katja, Paivi, Marja-Terttu and Pekka [59]. Consequently as the participation frequency in leisure increases, individual happiness levels also rise. Similarly, in a survey done by Huang and Carleton [52] for university students, it was suggested that there was a positive significant relationship between happiness and leisure activities. Sener et al. [88] revealed similar results in their research.

ANOVA analysis revealed that the HS scores of the participants differ statistically according to the variables of income. The average score obtained by the participants whose income was $1501 \mathrm{TL}$ or more is higher than that of those with a lower income level. Moreover, a MANOVA analysis revealed that the effect of income level on the LSS sub-dimension scores was significant. According to a one-way ANOVA analysis, the 'Psychological' and 'Aesthetic' sub-dimension scores differed significantly. In both sub-dimensions where a significant difference was discovered, the average scores of the participants with high levels of income were higher than those of other participants. According to these results, it can be said that both leisure satisfaction levels and personal happiness levels of those with high level of income are high. Diener and Diener [26] pointed out in their study that socio-economic status has a relatively strong relationship with personal happiness according to age and gender, and that the strongest socio-structural predictor of personal happiness might be income and social status. Accordingly, it was found that economic status perceived in this study was a factor that is connected with the personal happiness of university students. This finding has supported the outcomes of the research by Moller [74], Chow [18], Dost [33], and Paolini, Yanez and Kelly [78]. Individuals' ability to meet their basic needs and their ability to participate in the activities in which they can improve themselves is contingent on economic conditions. Therefore, it was not surprising that economic status is associated with individuals' and university students' happiness. Overall in this study, a significant and positive relationship was found between all dimensions of emotional intelligence and happiness. To sum up, it would not be wrong to predict the level of personal happiness will increase as the levels of leisure satisfaction of the participants increase.

According to Moller [74], the welfare of a nation depends on the fact that students are well and happy. Interest shown in the welfare of students with leadership characteristics is an investment in a country's future. The personal happiness of university students has great importance for society, and is an issue that must be taken seriously into consideration. If the leisure activities and leisure satisfaction are of such importance in terms of their contribution to personal happiness of the students, the following suggestions could be made in accordance with the results of this research;
In order to help university students to use their leisure time more meaningfully, universities and municipalities in particular can offer fully-equipped indoor and outdoor recreation centers and facilities by building them in convenient locations. Factors which prevent or encourage the participation of university students in leisure activities should be deeply analyzed. Factors causing solitude and an avoidance of leisure activities should be thoroughly analyzed and psycho-educational workshops promoting communication and social skills for students can be organized.

\section{Limitations and Future Studies}

This study was of significance in that it has been the first to deal with the relationship between leisure satisfaction and personal happiness. However, it is obvious that the outcomes obtained should be reinforced through other studies as well. Based on the results that were obtained, programs which aim to increase personal happiness, along with the leisure satisfaction variable, obstacles to leisure and the motivation variable can be dealt with, too. On the other hand, there are some limitations of this research. For example, the research was carried out with one sample composed only of university students. For this reason the results may not be pertinent for other demographics. Further research with different groups in Turkish culture is important. Alternatively, the study could be replicated in a variety of cultures and nations. Furthermore, studying the impact of leisure activities on happiness through experimental studies will also contribute to the literature.

\section{Acknowledgements}

I would like to thank Mrs. Monica Woods from Foreign Languages Department at Bilkent College for her assistance with proofreading and also special thanks Dr. Bulent Gurbuz for his assistance with the statistical analyses in this study.

\section{REFERENCES}

[1] Abdel - Khalek, A. M. (2006). Measuring happiness with a single-item scale. Social Behavior and Personality, 34(2), 139-150.

[2] Ardahan, F., Lapa, T.Y. (2010). Universite ogrencilerinin serbest zaman tatmin duzeylerinin cinsiyete ve gelire göre incelenmesi [Title in English: Investigation leisure satisfaction of university student by gender and income]. Hacettepe Journal of Sport Sciences, 21 (4), 129-136.

[3] Ardahan, F., Tekin, M. (1998). Resmi liseler ve ayni statudeki ozel kolejlerde calisan ogretmenlerin is tatmini boyutlari: Antalya ili ornegi [Title in English: Private and public school 
teachers' job satisfaction dimensions: Antalya case]. VII. Ulusal Egitim Bilimleri Kongresi, Konya.

[4] Argyle, M. (1987). The Psychology of Happiness. Routledge, London.

[5] Argyle, M. (1996). The sociology of the leisure. London: Penguin.

[6] Argyle, M., Martin, M., \& Crossland, J. (1989). Happiness as a function of personality and social encounters. In J. P. Forgas., J. M. Innes (Eds.), Recent advances in social psychology: An international perspective (pp. 189-203). Amsterdam: North Holland, Elsevier Science.

[7] Aristotle. (1998). Politics. (C. D. C. Reeve, Trans.). Indianapolis: Hackett.

[8] Ateca-Amestoy, V., Serrano-del-Rosal, R., \& Vera-Toscano, E. (2008). The leisure experience. The Journal of Socio-Economics, 37(1), 64-78.

[9] Aydin, D. (1999). Social network composition, social support and psychological well-being in first year METU students: A longitudinal investigation. Unpublished manuscript. METU, Ankara.

[10] Beard, J.G. \& Ragheb, M.G. (1980). Measuring leisure satisfaction. Journal of Leisure Research, 12, 20-33.

[11] Berg, E., Trost, M., Schneider I.E., \& Allison M.T. (2001). Dyadic exploration of the relationship of leisure satisfaction, leisure time, and gender to relationship satisfaction. Leisure Sciences, 23 : 35-46.

[12] Brown, B.A., \& Frankel B.G. (1993) Activity through the years: leisure, leisure satisfaction and life satisfaction. Sociology of Sport Journal, 10, 1-17.

[13] Buyukozturk, Ş., Cakmak, E., Akgun, O. E., Karadeniz, S. \& Demirel, F. (2012). Bilimsel arastirma yontemleri [Title in English: Scientific research methods]. Pegem, Ankara.

[14] Caldwell, L., Smith, E., \& Weissenger, E. (1992). The Relationship of Leisure Activities and Perceived Health of College Students. Society and Leisure, 15(2): 545-556.

[15] Caldwell, L.L. (2005). Leisure and health: Why is leisure therapeutic? British Journal of Guidance and Counseling, $33(1), 7-26$.

[16] Cenkseven, F. (2004). An investigation of predictors of subjective and psychological well-being of university students. Unpublished $\mathrm{PhD}$ thesis, Cukurova University, Adana.

[17] Cheng, H. \& Furnham, A. (2004). Perceived parental rearing style, self-esteem and self-criticism as predictors of happiness. Journal of Happiness Studies, 5, $1-21$.

[18] Chow, H. P. H. (2005). Life satisfaction among university students in a Canadian prairie city: A multivariate analysis. Social Indicators Research, 70, 139-150.

[19] Crossley, A. \& Landridge, D. (2005). Perceived sources of happiness: A network analysis. Journal of Happiness Studies, 6: $107-135$.

[20] Csikszentimihalyi, M. (1997). Happiness and creativity: Going with the flow. The Futurist, 31(5), 8-13.

[21] Csikszentmihalyi, M., \& Hunter, J. (2003). Happiness in everyday life: The uses of experience sampling. Journal of Happiness Studies, 4, 185-199.

[22] Currier, J. (2004). Motherhood, stress and the exercise experience: freedom or constraint? Leisure Studies, 23(3), 225-242.

[23] DiBona, L. (2000). What are the benefits of leisure? An exploration using the leisure satisfaction scale. British Journal of Occupational Therapy, 63 (2), 50-58.

[24] Diener, E. (1984). Subjective well-being. Psychological Bulletin, 95, 542-575.

[25] Diener, E. (2000). Subjective well-being: The science of happiness and a proposal for a national index. American Psychologist, 55, 34-43.

[26] Diener, E., \& Diener, C. (1996). Most people are happy. Psychological Science, 7: 181-188.

[27] Diener, E., \& Seligman, M. (2002). Very happy people. Psychological Science, 13, 81-84.

[28] Diener, E., Diener, M., \& Diener, C. (1995). Factors predicting the subjective well-being of nations. Journal of Personality and Social Psychology, 69, 851- 864.

[29] Diener, E., Emmons, R.A., Larsen, R.J., Griffin, S., (1985). The Satisfaction with Life Scale. Journal of Personality Assessment, 49 (71-75).

[30] Diener, E., Oishi, S., \& Lucas, E. R. (2003). Personality, Culture, and Subjective Well-Being Emotional and Cognitive Evaluations of Life. Annual Review of Psychology, 54: 403425.

[31] Dogan, T. \& Cotok, N. (2011). Adaptation of the short form of the Oxford Happiness Questionnaire into Turkish: A validity and reliability study. Journal of Turkish Psychological Counseling and Guidance, 4(36), 165-172.

[32] Dogan, T. (2012). Examination of Psychometric Properties of the Turkish Version Form of the Oxford Happiness Questionnaire in University Students, Journal of Psychiatry \& Neurological Sciences, 25 (4): 297-304.

[33] Dost, M.T. (2006). Subjective Well-Being among University Students. Hacettepe Universitesi Egitim Fak. Dergisi, 31:188-197.

[34] Edginton, C.R. (2007). The World Leisure Organization: Promoting Social, Cultural and Economic Transformation. Licere, Belo Horizonte, 10 (2).

[35] Fugl-Meyer, A. R., Melin, R., \& Fugl-Meyer, K. S. (2002). Life satisfaction in 18 to 64 year old Swedes: In relation to gender, age, partner and immigrant status. Journal of Rehabilitation Medical, 34, 239-246.

[36] Giblin, L.T. (1985). İnsan iliskilerinde kendine guven ve guc elde etmenin yollari [How To Have Confidence and Power In Dealing With People]. 2. Ed. Translate: Gupgupoglu, İ. (2008). İstanbul: Sistem Publishing.

[37] Godbey, G. (2003). Leisure in your life: An exploration (6th ed.). State College, PA: Venture.

[38] Godin, G. (1997). Godin Leisure Time Exercise Questionnaire. Med. Sci. in Sports Exerc. 26 (Jun Supply), 36-38.

[39] Godin, G., \& Shephard, R.J. (1985). A simple method to 
assess exercise behavior in the community. Canada Journal of Applied Sport Sciences. 10: 141-146.

[40] Gokce, H., \& Orhan, K. (2011). Validity and Reliability Study of the Leisure Satisfaction Scale (LSS) into Turkish. Hacettepe J. of Sport Sciences, 22 (4), 139-145.

[41] Gordon, W. R., \& Catalbiano, M. L. (1996). Urban and rural differences in adolescent self-esteem, leisure boredom, and sensation seeking as predictors of leisure time usage and satisfaction. Adolescence, 31, 883-901.

[42] Grinde, B. (2002). Happiness in the perspective of evolutionary psychology. Journal of Happiness Studies, 3, $331-354$

[43] Gurbuz, B. \& Henderson, K. (2013). Exploring the Meanings of Leisure among Turkish University Students. Croatian Journal of Education, 15(4), 927-957.

[44] Hallab, Z. (2006). Catering to the healthy-living vacationer. Journal of Vacation Marketing, 12(1), 71-91.

[45] Hampton, N. Z., \& Marshall, A. (2000). Culture, gender, self-efficacy and life satisfaction: A comparison between Americans and Chinese people with spinal cord injuries. Journal of Rehabilitation, 66 (3): 21-29.

[46] Headey, B., Wearing, A. (1992). Understanding happiness. Melbourne: Longman Cheshire.

[47] Hills, P. \& Argyle, M. (2002). The Oxford Happiness Questionnaire: a compact scale for the measurement of psychological well-being. Personality and Individual Differences, 33, 1073- 1082

[48] Hills, P., \& Argyle, M. (1998). Positive moods derived from leisure and their relationship to happiness and personality. Personality and Individual Differences, 25, 523-535.

[49] Hintikka, J. (2001). Religious attendance and life satisfaction in the Finnish general population. Journal of Psychology and Theology, 29 (2), 158.

[50] Holder, M.D., Coleman, B., \& Sehn, Z. L. (2009). The contributions of active and passive leisure to children's well-being. Journal of Health Psychology, 14(3), 378-386.

[51] Horne, J. (1998). Understanding leisure time and leisure space in contemporary Japanese society. Leisure Studies, 17, 37-52.

[52] Huang, C.Y., \& Carleton, B. (2003). The Relationships among Leisure Participation, Leisure Satisfaction, and Life Satisfaction of College Students in Taiwan. Journal of Exercise Science and Fitness, 1(2), 129-132.

[53] Huebner, E. S. (1991). Correlates of life satisfaction in children. School Psychology, Quarterly, 6: 103-111.

[54] Hultsman, W. Z. (1993). The influence of others as a barrier to recreation participation among early adolescents. Journal of Leisure Research, 27, 228-244.

[55] Iso-Ahola, S. E. (1980). The social psychology of leisure and recreation. Dubuque, Iowa: Wm C. Brown Company.

[56] Iwasaki, Y. (2007). Leisure and quality of life in an international and multicultural context: What are major pathways linking leisure to quality of life? Social Indicators Research, 82, 233-264.

[57] Kabanoff, B. (1982). Occupational and sex differences in leisure needs and leisure satisfaction. Journal of Occupational Behavior, 3: 233 - 245.

[58] Karakatipoglu, A. Z. (2002). Self-construals, perceived parenting styles and well-being in different cultural and socioeconomic contexts. Unpublished $\mathrm{PhD}$ thesis. METU, Ankara.

[59] Katja, R., Paivi, A. K., Marja-Terttu, T., \& Pekka, L. (2002). Relationships among adolescent' subjective wellbeing, health behavior and school satisfaction. Journal of School Health, 72 (6), 243-250.

[60] Kaya, S. (1998). The Factors that Influencing Student Participation in Physical Recreational Activity Programs at Bilkent University. Unpublished Master's Thesis. Izzet Baysal University, Bolu.

[61] Kim, K.R. (2003). The relationship between the self-efficacy and mental health of youth participation in sports (Unpublished dissertation). Yong-In University, Korea

[62] Koker, S. (1991). Comparison of life satisfaction levels of normal adolescents and adolescents with problems. Unpublished master' thesis. Ankara University, Ankara.

[63] Lin, Y. M. (2004). The study of the leisure benefit and happiness of swimmers. Unpublished Master's Thesis. National Yunlin University of Science and Technology. Yunlin.

[64] Liu, H., Yeh, C., Chick, G. E. \& Zinn, H. C. (2008). An exploration of meaning of leisure: A Chinese perspective. Leisure Sciences, 30, 482-488.

[65] Lloyd, K.M, \& Auld C.J. (2002). The role of leisure in determining quality of life: Issues of context and measurement. Social Indicators Research, 57, 43-71.

[66] Lu, L., \& Argyle, M. (1994). Leisure satisfaction and happiness as a function of leisure activity. Kaohsiung Journal Medicine Science, 10, 89-96.

[67] Lu, L., \& Hu CH. (2005). Personality, leisure experiences and happiness. Journal of Happiness Studies, 6, 325-342.

[68] Lu, L., \& Shih, J. B. (1997). Personality and happiness: Is mental health a mediator? Pers. Indiv. Differ. 22: 249-256.

[69] Lyubomirsky, S. (2001) Why are some people happier than others: The role of cognitive and motivational processes in well being. American Psychologist, 56, 239-249.

[70] Lyubomirsky, S. (2007). The How of Happiness: A scientific approach to getting the life you want. Penguin Books, NY.

[71] Lyubomirsky, S., King, L. A., \& Diener, E. (2005). The benefits of frequent positive affect: Does happiness lead to success? Psychological Bulletin, 131(6), 803-851.

[72] Lyubomirsky, S., Sheldon, K. M., \& Schkade, D. (2005). Pursuing happiness: The architecture of sustainable change. Review of General Psychology, 9, 111-131.

[73] Mieczkowski, Z. (1990). World Trend in Tourism and Recreation. New York: Peter Lang Publishing.

[74] Moller, V. (1996). Life satisfaction and expectations for the future in sample of university students: A research note. South African Journal of Sociology, 27 (1), 109-125.

[75] Murphy, H. (2003). Exploring Leisure and Psychological 
Health and Well-being: Some Problematic Issues in the Case of Northern Ireland. Leisure Studies, 22(1): 37-50.

[76] Myers, D.G., \& Diener, E. (1995). Who is happy? Psychological Science, 6 (1), 10-17.

[77] Nesbit, G. (1993). What effects do our programs have on our participants? NIRSA Journal, 17 (3), 13-16.

[78] Paolini, L., Yanez, A. P. \& Kelly, W. E. (2006). An examination of worry and life satisfaction among college students. Individual Differences Research, 4 (5), 331-339

[79] Parham L.D. (1996). Perspective on Play. In Zemke, R. and Clark, F., (eds). Occupational Science: The Evolving Discipline. Philadelphia, PA: FA Davis Company.

[80] Peterson, C.P., N. K. \& Seligman, M. E. P. (2005). Orientations to happiness and life satisfaction: The full life versus the empathy life. Journal of Happiness Studies, 6, $25-$ 41.

[81] Pichly, A. (2002). Individuals can benefit physically, mentally, emotionally, spiritually and socially from a comprehensive leisure education program implemented in the schools during childhood. A research project report submitted in partial fulfillment of the requirements for the successful completion of RLS 209.

[82] Reich, J. W. \& Zautra, A. (1981). Life events and personal causation: some relationships with satisfaction and distress. Journal of Personality and Social Psychology, 41, 1002-1012.

[83] Riddick, C. C. (1986). Leisure satisfaction precursors. Journal of Leisure Research, 18(4): 259 - 265.

[84] Roberts, K. (2006). Leisure in contemporary society (2nd ed). Wallingford: CABI Publishing.

[85] Robinson, J.P., \& Godbey, G. (1999). Time for life: The surprising ways Americans use their time. PA: The Pennsylvania State University Press.

[86] Searle, M.S., Mactavish, J. B., \& Brayley, R. E. (1993). Integrating ceasing participation with other aspects of leisure behavior: A replication and extension. Journal of Leisure Research, 25 (4), 389-404.

[87] Seligman, M. E. P. (2011). Flourish: A visionary new understanding of happiness and well-being. New York: Simon \& Schuster.
[88] Sener, A., Terzioglu, R.G., \& Karabulut, E. (2007). Life Satisfaction and Leisure Activities during Men's Retirement: A Turkish Sample. Aging \& Mental Health, 11(1), p.p. 30-36.

[89] Sheldon, K. M., \& Lyubomirksy, S. (2006). Achieving sustainable gains in happiness: Change your actions, not your circumstances. Journal of Happiness Studies, 7(1), 55-86.

[90] Siegenthaler, K. L. (1997). Health benefits of leisure. Parks and Recreation, 32(1), $24-31$.

[91] Spiers, A., \& Walker, G. J. (2008). The effects of ethnicity and leisure satisfaction on happiness, peacefulness, and quality of life. Leisure Sciences, 31(1), 84-99.

[92] Stebbins, R. A. (2014). Leisure, happiness, and positive lifestyle. In S. Elkington, \& S. J. Gammon (Eds.). Contemporary perspectives in leisure: Meanings, motives, and lifelong learning. New York: Routledge.

[93] Taylor, S. E., \& Brown, J. D. (1988). Illusion and well-being: A social psychological perspective on mental health. Psychological Bulletin, 103, 193-210.

[94] Todaro, E. (1993). The impact of recreational sports on student development: A theoretical model. NIRSA Journal, 17 (3), 23-26.

[95] Veenhoven, R. (2008). Healthy happiness: Effects of happiness on physical health and the consequences for preventive health care. Journal of Happiness Studies, 9: 449-469.

[96] Vong, Tze N. (2005). Leisure satisfaction and quality of life in Macao, China. Leisure Studies, 24 (2): 195-207.

[97] Walker, G. J. \& Wang, X. (2009). The meaning of leisure for Chinese/Canadians. Leisure Sciences, 31, 1-18.

[98] Wang, F., Orpana, H. M., Morrison, H., de Groh, M., Dai, S., \& Luo, W. (2012). Long-term association between leisure-time physical activity and changes in happiness: Analysis of the prospective National Population Health Survey. American Journal of Epidemiology, 176(12): 1095-1100.

[99] Wilson, D. (1994). Leisure benefits and student development. NIRSA Journal, 19 (1), 3 